\title{
Impact of the introduction of pneumococcal conjugate vaccine on immunization coverage among infants Nancy D Lin ${ }^{1}$, Ken Kleinman ${ }^{1}$, K Arnold Chan ${ }^{2}$, Xian-Jie Yu ${ }^{1}$, Eric K France ${ }^{3}$, Stanley $\mathrm{Xu}^{3}$, Feifei Wei ${ }^{4}$, John Mullooly ${ }^{5}$, Jeanne Santoli ${ }^{6}$, Tracy A Lieu*1 and the Vaccine Safety Datalink Group
}

Address: ${ }^{1}$ Department of Ambulatory Care and Prevention, Harvard Pilgrim Health Care and Harvard Medical School, Boston, MA, USA, ${ }^{2}$ Harvard School of Public Health, Boston, MA, USA, ${ }^{3}$ Kaiser Permanente, Denver, Kaiser Permanente, Denver, CO, USA, ${ }^{4}$ HealthPartners Research Foundation, Minneapolis, MN, USA, ${ }^{5}$ Center for Health Research, Kaiser Permanente Northwest, Portland, OR, USA and ${ }^{6}$ National Immunization Program, Centers for Disease Control and Prevention, Atlanta, GA

Email: Nancy D Lin - nlin@stanford.edu; Ken Kleinman - ken_kleinman@harvardpilgrim.org; K Arnold Chan - kachan@hsph.harvard.edu; Xian-JieYu - yuxxi2002@yahoo.com; Eric K France - eric.k.france@kp.org; Stanley Xu - stan.xu@kp.org;

Feifei Wei - feifei.wei@healthpartners.com; John Mullooly - john.mullooly@kpchr.org; Jeanne Santoli - zmd4@cdc.gov;

Tracy A Lieu* - tracy_lieu@ harvardpilgrim.org

* Corresponding author

Published: 28 November 2005

BMC Pediatrics 2005, 5:43 doi:10.1186/147I-2431-5-43

This article is available from: http://www.biomedcentral.com/I47/-243I/5/43

(c) 2005 Lin et al; licensee BioMed Central Ltd.

This is an Open Access article distributed under the terms of the Creative Commons Attribution License (http://creativecommons.org/licenses/by/2.0), which permits unrestricted use, distribution, and reproduction in any medium, provided the original work is properly cited.
Received: 05 July 2005

Accepted: 28 November 2005

\begin{abstract}
Background: The introduction of pneumococcal conjugate vaccine (PCV) to the U.S. recommended childhood immunization schedule in the year 2000 added three injections to the number of vaccinations a child is expected to receive during the first year of life. Surveys have suggested that the addition of PCV has led some immunization providers to move other routine childhood vaccinations to later ages, which could increase the possibility of missing these vaccines. The purpose of this study was to evaluate whether introduction of PCV affected immunization coverage for recommended childhood vaccinations among 13-month olds in four large provider groups.
\end{abstract}

Methods: In this retrospective cohort study, we analyzed computerized data on vaccinations for 33,319 children in four large provider groups before and after the introduction of PCV. The primary outcome was whether the child was up to date for all non-PCV recommended vaccinations at 13 months of age. Logistic regression was used to evaluate the association between PCV introduction and the primary outcome. The secondary outcome was the number of days spent underimmunized by 13 months. The association between PCV introduction and the secondary outcome was evaluated using a two-part modelling approach using logistic and negative binomial regression.

Results: Overall, $93 \%$ of children were up-to-date at 13 months, and $70 \%$ received all non-PCV vaccinations without any delay. Among the entire study population, immunization coverage was maintained or slightly increased from the pre-PCV to post-PCV periods. After multivariate adjustment, children born after PCV entered routine use were less likely to be up-to-date at 13 months in one provider group (Group C: $\mathrm{OR}=0.5 ; 95 \% \mathrm{Cl}: 0.3-0.8$ ) and were less likely to have received all vaccine doses without any delay in two Groups (Group B: $\mathrm{OR}=0.4,95 \% \mathrm{Cl}$ : $0.3-0.6$; Group C: $O R=0.5,95 \% \mathrm{Cl}: 0.4-0.7)$. This represented $3 \%$ fewer children in Group C who were 
up-to-date and 14\% (Group C) to 16\% (Group B) fewer children who spent no time underimmunized at 13 months after PCV entered routine use compared to the pre-PCV baseline. Some disruptions in immunization delivery were also observed concurrent with temporary recommendations to suspend the birth dose of hepatitis $B$ vaccine, preceding the introduction of PCV.

Conclusion: These findings suggest that the introduction of PCV did not harm overall immunization coverage rates in populations with good access to primary care. However, we did observe some disruptions in the timely delivery of other vaccines coincident with the introduction of PCV and the suspension of the birth dose of hepatitis B vaccine. This study highlights the need for continued vigilance in coming years as the U.S. introduces new childhood vaccines and policies that may change the timing of existing vaccines.

\section{Background}

The addition of pneumococcal conjugate vaccine (PCV) to the U.S. recommended childhood immunization schedule in the year 2000 added three injections to the number of shots a child is expected to receive during the first year of life. Whereas seven to ten injections were recommended during the first year of life prior to introduction of PCV, between ten and thirteen injections are now recommended, depending on use of combination vaccines. With the addition of pneumococcal vaccination, the youngest children may receive up to five injections at a single office visit[1].

Simultaneous administration of vaccines is recommended to facilitate early protection against vaccine-preventable disease[2]. At the same time, administration of multiple injections may create distress for children and parents, and many parents and providers have previously expressed concern regarding the administration of four vaccines at a single visit [3-5]. It is unclear how increased crowding of the childhood immunization schedule and safety concerns about multiple injections related to the introduction of PCV have affected immunization delivery. Two regional provider surveys suggested that physicians who administer PCV may delay other vaccinations, [4,6] although a different, national survey found that most physicians who adopted PCV in their practices would administer four or more injections at the 2-month visit[7]. The objective of this study was to evaluate whether the introduction of PCV affected immunization delivery in actual practice among large populations of children in several provider groups.

\section{Methods}

\section{Study population}

This study included children enrolled in four large provider groups: Harvard Vanguard Medical Associates (Boston, MA), HealthPartners (Minneapolis, MN), Kaiser Permanente of Colorado (Denver, CO), and Kaiser Permanente Northwest (Portland, OR). These sites participate in the Centers for Disease Control and Prevention
Vaccine Safety Datalink Project, in which individual-level vaccination, demographic, and medical data are shared to facilitate vaccine safety and other vaccine-related epidemiologic research[8].

We studied infants who were born into one of the four provider groups between October 1996 and November 2000 and had received at least one polio vaccination, where receipt of polio vaccination was used as an indicator that a child received immunizations that were recorded by the provider group information systems $(\mathrm{n}=$ $86,561)$. To ensure that the most complete immunization information was available, the study population was additionally restricted to children continuously enrolled throughout their first year of life $(n=38,588)$. The study protocol was approved by the institutional review boards at the four participating sites and the Centers for Disease Control and Prevention.

\section{Definition of Post-PCV and Pre-PCV exposure cohorts}

Each child was assigned to one of two birth cohorts based on the timing of their birth relative to the regulatory approval of PCV in February 2000[9]. Individuals who were born between October 1996 and January 2000 were assigned to the "pre-PCV" birth cohort. Children born between February and November 2000 were assigned to the "post-PCV" birth cohort.

While introduction of PCV added three new vaccine injections, use of the hepatitis B-Haemophilus influenzae type B (Hib) combination vaccine can offset the increase in vaccine injections a child requires to be fully immunized during the first year of life. Hepatitis B-Hib combination vaccine was available throughout the study period in one provider group and was implemented in two other provider groups during the study period; in the fourth provider group, it was not available at all. Table 1 describes how the expected number of injections varied based on provider group-specific availability of the hepatitis B-Hib combination vaccine during the pre-PCV and the postPCV periods. 
Table I: Variation in the expected number of vaccine injections during the first year of life, by provider group and PCV policy period

Number of vaccine injections expected during the first year of life

\begin{tabular}{lcc}
\hline Group & Pre-PCV birth cohort & Post-PCV birth cohort \\
\hline Group A & $7 *$ or 10 & $10 *$ or 13 \\
Group B $\ddagger$ & 10 & 13 \\
Group C $\$$ & 10 & $10 *$ or 13 \\
Group DII & $7 *$ or 10 & $10 *$ or 13 \\
\hline
\end{tabular}

A child born during the pre-PCV period is expected to receive 3 DTP vaccinations, 2 polio vaccinations, 3 Hib vaccinations, and 2 hepatitis $B$ vaccinations during the first year of life. Introduction of PCV added three new vaccine injections.

* Replacement of the separate hepatitis B and Hib vaccines during the first year of life with 2 doses of hepatitis B-Hib combination vaccine reduces the number of vaccine injections expected during the first year of life to 7 shots in the pre-PCV period and 10 in the post-PCV period.

† Hepatitis B-Hib combination vaccine available throughout the study period.

‡ Hepatitis B-Hib combination vaccine never available during the study period.

$\S$ Hepatitis B-Hib combination vaccine available starting in 2000 following PCV introduction, based on descriptive analyses.

II Hepatitis B-Hib combination vaccine available starting in mid-1999 prior to PCV introduction, based on descriptive analyses.

\section{Definition of immunization coverage measures}

We assessed the impact of the introduction of PCV on two measures of immunization coverage at 13 months of age: (1) up-to-date status and (2) time spent underimmunized[10].

Vaccination histories were identified using the immunizations databases for each provider group. When vaccine entries of the same type were recorded within seven days of one another, the later entry was assumed to represent a duplicate record and was excluded $(0.006 \%-0.56 \%$, by vaccine type). In addition, vaccinations that were administered before the minimum recommended age or earlier than the minimum recommended between-vaccination interval, allowing for a four-day grace period,[1,2] were considered to be invalid. Only the remaining vaccinations for eligible individuals were included in our analyses.

In general, a child was considered to be up-to-date for non-PCV recommended vaccinations at 13 months of age if they received all of the following: 3 diphtheria and tetanus toxoids and acellular or whole cell pertussis (DTP) vaccinations; 2 polio vaccinations; 2 hepatitis $B$ vaccinations; and $3 \mathrm{Hib}$ vaccinations. Children who received the hepatitis B-Hib combination vaccine were considered upto-date for the hepatitis $\mathrm{B}$ and Hib vaccinations if they received 2 hepatitis $\mathrm{B}$ vaccine doses and $2 \mathrm{Hib}$ vaccine doses by age 13 months.

The up-to-date measure includes only those vaccine doses with recommended age ranges contained wholly included within the 13-month individual follow-up period. Doses with recommended age ranges that spanned the 13month birthday (e.g., third dose of hepatitis B vaccine recommended between 6 and 18 months of age) were not included because children who had not yet received these doses by age 13 months would not be considered late. As a result, the up-to-date definition corresponds to vaccinations recommended between birth and 6 months of age. PCV was not included in the outcome definition because the primary study objective was to evaluate whether addition of PCV affected adherence to existing vaccine recommendations.

The secondary outcome, time spent underimmunized, was defined as the number of days a child spent underimmunized for at least one non-PCV recommended vaccination by 13 months of age and is the complement of a previously documented outcome measure, cumulative time spent up-to-date[11]. Because it measures the amount of vaccination delay rather than immunization status at a single point in time, this outcome is expected to be more sensitive than up-to-date status at 13 months. Operationally, we calculated time spent underimmunized for each individual by assessing the child's up-to-date status for the non-PCV recommended vaccinations on each day from birth up to their 13-month birthday based on the U.S. recommended childhood immunization schedule[1]. We then summed the number of days on which the child was not up-to-date for at least one non-PCV recommended vaccination. When the recommended age range was specified in months, a vaccination was considered age-appropriate if it was given prior to the end of the maximum recommended month, where 30.5 days represented one month. Days spent underimmunized began to accumulate following the end of this 30.5-day grace period. For example, the first dose of diphtheria and tetanus toxoids and acellular pertussis combination vaccine (DTaP) is recommended at 2 months. A child who receives a valid DTaP by 91 days of age (i.e., (2 months* $30.5)+30.5$ day grace period $=91.5$ days $)$ is considered to have been vaccinated age-appropriately and does not accumulate any underimmunized time. By comparison, a child who receives their first DTaP at 94 days of age has accumulated 2 days of underimmunized time (i.e., underimmunized for days 92 and 93, and up-to-date on day 94 for the first dose of DTaP).

\section{Description of covariates}

In addition to the PCV exposure cohorts, other vaccine policy and temporal factors related to immunization cov- 
erage were considered. Between July and September 1999, providers were encouraged to delay initiation of hepatitis B vaccination for low-risk infants from birth to 2-6 months of age because of safety concerns about thimerosal[12]. While resumption of hepatitis B birth vaccination practices was recommended after regulatory approval of the first thimerosal-free hepatitis B vaccine formulation in September 1999,[13] reinstatement of universal birth vaccination policies occurred slowly [14-17]. Two indicators were included in the regression models to account for potential disruptions in immunization coverage during the pre-PCV period, related the temporary hepatitis $\mathrm{B}$ birth dose suspension ("HB delay" cohort: date of birth between July - September 1999) and to incomplete resumption of hepatitis B birth vaccination practices ("HB carryover" cohort: date of birth between October 1999 January 2000).

Temporal trends in immunization coverage were modeled using four variables based on birth month cohort: a linear slope was fit for the entire study period, and three additional linear trends were included to estimate changes in slope during the HB delay, HB carryover, and post-PCV periods relative to the pre-PCV baseline trend.

An indicator variable was included to account for a potential change in the level of immunization coverage after integration of PCV into routine practice ("PCV routine": July - November 2000) compared to the initial PCV adoption period ("PCV adoption": February - June 2000). Selection of the July 2000 birth cohort as the transition point after which PCV entered routine use was based on descriptive analyses of the adoption of PCV in the participating provider groups.

Finally, seasonal variation in immunization scheduling could affect the timeliness of vaccination and was entered into the time spent underimmunized regression models using indicator variables for calendar month of birth.

Figure 1 illustrates how the hepatitis B and PCV policy variables are temporally related.

\section{Statistical analysis}

Logistic regression was used to assess the association between PCV introduction and a child's probability of being up-to-date at 13 months.

For the second outcome, time spent underimmunized, we expected that the majority of children would be vaccinated age-appropriately (i.e., zero days spent underimmunized by 13 months), and a two-part modelling approach[18] was applied. First, a logistic regression model was used to assess the association between PCV introduction and a child's probability of having received all vaccines age-appropriately by 13 months of age. Then, among children who spent at least one day underimmunized, negative binomial regression was used to evaluate the impact of PCV introduction on the discrete outcome, number of days spent underimmunized by 13 months. Negative binomial regression accounts for overdispersion in the data[19] and provides relative rate estimates for the association between PCV introduction and the number of days spent underimmunized.

Analyses were stratified by provider group because differences in baseline immunization coverage, differing concern regarding multiple injections, and provider groupspecific decisions to use combination vaccines may have differentially affected the impact of PCV introduction across the provider groups. To allow comparisons across sites, the set of variables included in the regression analysis for each outcome was fixed across the provider groups.

Based on the regression model, we estimated the effect of introduction of PCV at two points - (1) immediately following PCV introduction (February 2000 birth cohort) and (2) after PCV was integrated into routine use (July 2000 birth cohort) - comparing each to the outcome as predicted from the pre-PCV baseline trend. Comparison of the PCV routine use period to the predicted baseline trend was considered of primary interest because it measures the impact of addition of $\mathrm{PCV}$, allowing for a period of adjustment to the new PCV policy. Figure 2 illustrates the calculation of these two contrasts for the up-to-date outcome as an example. Given that the baseline proportion of children who were up-to-date or who were vaccinated age-appropriately was expected to be high, under these conditions, odds ratios should not be interpreted as approximately the relative risk. Absolute differences in coverage were also provided, comparing the probability fitted from multivariate regression models based on the observed data ("fitted probability") to the "predicted probability" extrapolated from the baseline trend (e.g., absolute difference Feb2000 $=$ [fitted probability $]_{\mathrm{Feb} 2000}$ [predicted probability $\left.]_{\mathrm{Feb} 2000}\right)$. All analyses were performed using SAS software, Version 8.2 of the SAS System for Windows (SAS Institute, Cary, NC).

\section{Results}

\section{Study population and adoption of PCV}

In the four provider groups, 38,588 children met study inclusion criteria. Due to the identification of a potential disruption in the immunization tracking system during the early part of the study period in one of the provider groups, the study population for that site (Group D) was additionally restricted to children born between November 1998 and November 2000. This resulted in a final study population of 33,319 children. 


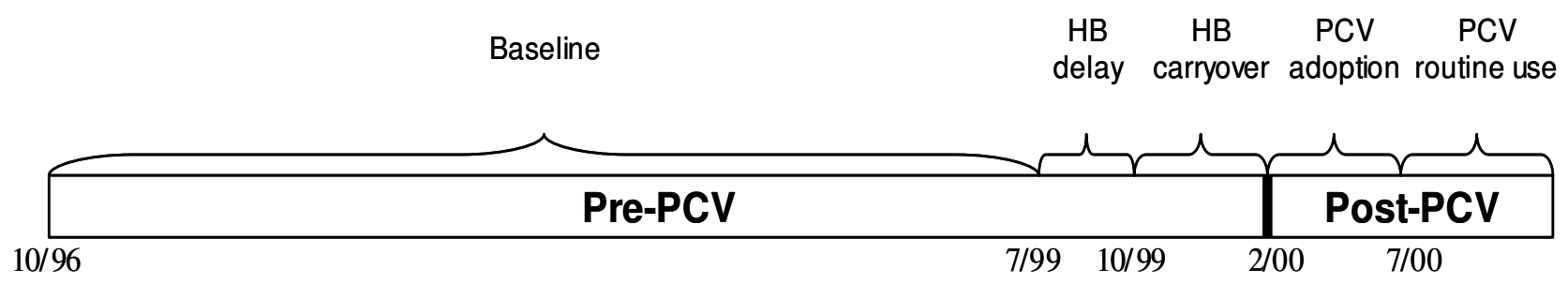

\section{Figure I}

Timing of PCV introduction and hepatitis B policy periods. "Pre-PCV" and "Post-PCV" describe the timing of the exposure birth cohorts. The "pre-PCV" cohort includes children born prior to introduction of pneumococcal conjugate vaccine (date of birth between October 1996 - January 2000) while the "post-PCV" cohort includes children born after introduction of pneumococcal conjugate vaccine to the end of the study period (date of birth between February - November 2000). "HB delay" refers to children born during the temporary hepatitis B birth dose suspension (July - September I999). "HB carryover" refers to children born after reinstatement of hepatitis B birth vaccination recommendations and before introduction of pneumococcal conjugate vaccine (October 1999 - January 2000). "PCV adoption" represents the first five months following introduction of pneumococcal conjugate vaccine and the period of initial uptake of pneumococcal conjugate vaccine in the four study sites (date of birth between February - June 2000). "PCV routine" represents the five-month period after adoption of pneumococcal conjugate vaccine had occurred (date of birth between July - November 2000).

Following its introduction in February 2000, the rate of adoption of PCV varied but was relatively rapid across the four sites. Among children born in July 2000, over $85 \%$ of children in each of three provider groups (Groups A, B, and D) received PCV at their 2-month visit. In Group C, while only $24 \%$ of the July 2000 birth cohort had received PCV at a 2-month visit, $76 \%$ in the August 2000 cohort had done so. Notwithstanding the age at which the PCV series was initiated, between 92\% (Group C) and 96\% (Group D) of the July 2000 birth cohort had received three shots of PCV by 13 months.

\section{Impact of PCV recommendations on probability of being up-to-date at 13 months}

Overall, 93\% of children were up-to-date at age 13 months. In each provider group, the percent of 13-montholds who were up-to-date either was maintained or increased slightly from the pre-PCV to the post-PCV cohorts (Figure 3).

In Group C, children born at the start of the PCV adoption period were less likely to be up-to-date at 13 months compared to the pre-PCV baseline after multivariate adjustment for the HB delay and carryover periods $(\mathrm{OR}=0.5$, 95\% CI: 0.4 - 0.8) (Table 2). This decrease persisted even after PCV entered routine use (Group C: OR $=0.5,95 \%$ CI: $0.3-0.8$ ), representing 3\% fewer children in Group C who were up-to-date compared to the predicted baseline trend. Additional analyses indicated that children in Group $\mathrm{C}$ were less likely to be up-to-date in the HB delay $(\mathrm{OR}=0.4 ; 95 \% \mathrm{CI}: 0.3-0.6)$ and $\mathrm{HB}$ carryover $(\mathrm{OR}=$ 0.25 ; 95\% CI: $0.17-0.35)$ periods compared to baseline, preceding the introduction of PCV. This suggests that the decrease observed in post-PCV period in Group $\mathrm{C}$ may have been due to the lingering effects of the hepatitis $\mathrm{B}$ birth dose suspension. In contrast, PCV introduction was not significantly associated with a child's probability of being up-to-date at 13 months in the three other provider groups.

\section{Impact of PCV recommendations on time spent underimmunized by 13 months}

Overall, 70\% of children received all non-PCV recommended vaccinations without incurring any underimmunized time. Among the 30\% of children who were ever delayed for at least one vaccination, a median of 122 days (interquartile range: 33 - 212) was spent underimmunized during the first 13 months of life.

Multivariate-adjusted results are provided only for Groups A, B, and C because the truncated study period for Group D limited our ability to fit the full multivariate model for this population (Table 3 ). Children born at the start of the PCV adoption period were less likely to receive all vaccinations without delay in Group B (OR = 0.4, 95\% CI: $0.3-$ $0.5)$ and in Group C (OR = 0.33, 95\% CI: $0.26-0.42)$. These differences persisted through the start of the PCV routine period (Group B OR $=0.4,95 \% \mathrm{CI}$ : $0.3-0.6$; Group C OR $=0.5,95 \% \mathrm{CI}: 0.4-0.7)$, representing $16 \%$ (Group B) and 14\% (Group C) fewer children among the July 2000 birth cohort who spent no time underimmunized compared to baseline. In Group A, no difference in timeliness of immunization delivery was noted following PCV introduction. 


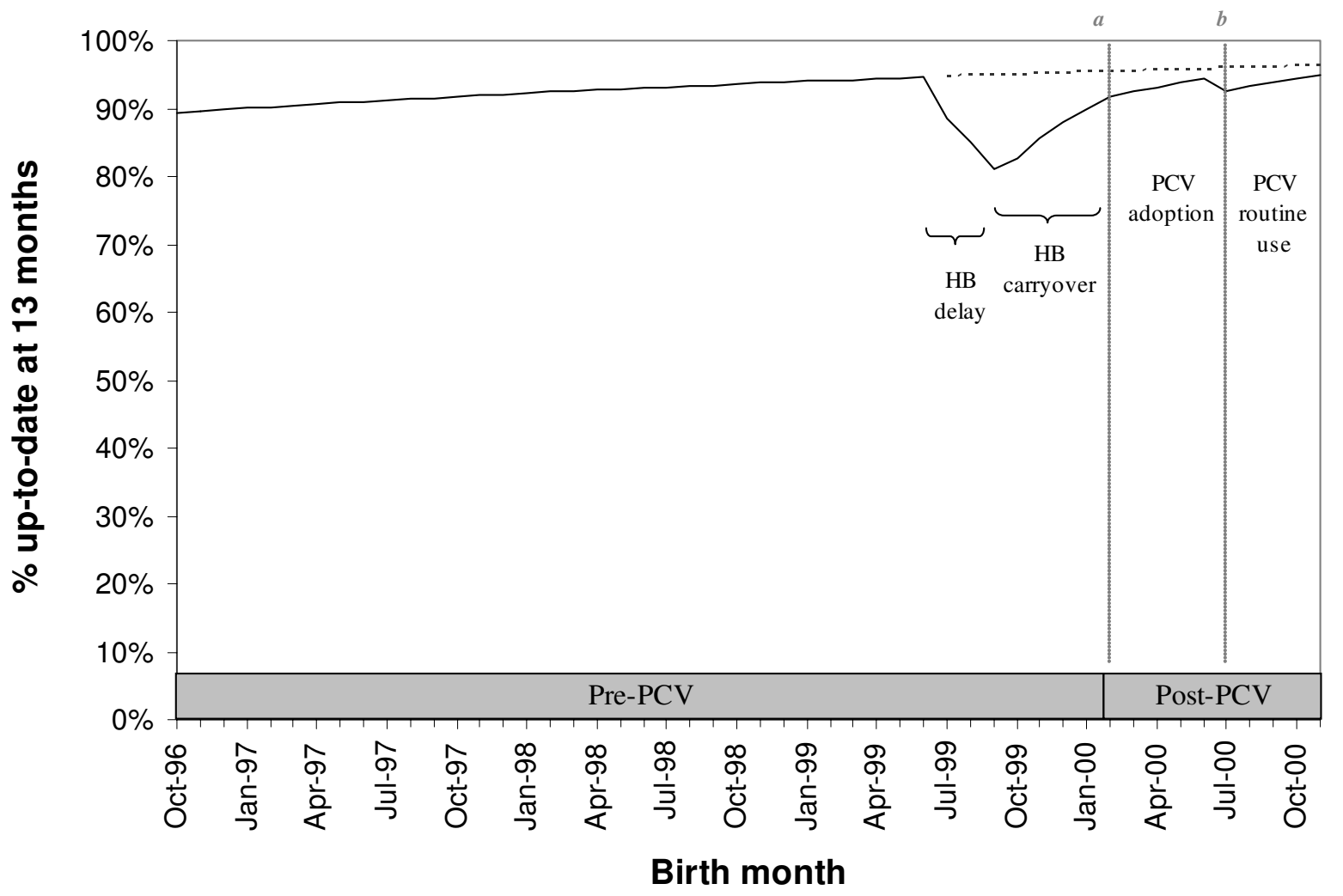

Fitted ….... Predicted

Figure 2

PCV introduction and immunization coverage: illustration of primary contrasts. Graph uses data from Group $\mathrm{C}$ as an example. ---: coverage based on multivariate regression models and the observed data. - - - : coverage predicted from the pre-PCV baseline trend. Time point a: February 2000 birth cohort, start of the PCV adoption period. Contrast a compares immunization coverage for the February 2000 birth cohort based on the observed data to that predicted from the pre-PCV baseline trend. Time point b: July 2000 birth cohort, start of the PCV routine period. Contrast $b$ compares immunization coverage for the July 2000 birth cohort based on the observed data to that predicted from the pre-PCV baseline trend.

Among children ever-delayed, children born during the PCV adoption period in Group C spent 1.5 times as many days underimmunized ( $\mathrm{CI}: 1.3-1.8$ ) compared to the predicted baseline trend. This increase in days spent underimmunized persisted among the PCV routine use cohort compared to the baseline trend (RR: 1.4, 95\% CI: $1.2-1.8$ ), representing a delay of 103 days versus 73 days on average, among children in Group $\mathrm{C}$ who were everunderimmunized. In contrast, no significant difference in the number of days spent underimmunized was found in the other two Groups, for either the PCV adoption cohort (Group A RR: 1.1, 95\% CI: 0.7-1.7; Group B RR: 1.1, 95\% CI: $0.8-1.4$ ) or the PCV routine use cohort (Group A RR:
1.4, 95\% CI: 0.8-2.2; Group B RR: 0.9; 95\% CI: 0.6-1.2), compared to the baseline trend.

\section{Introduction of PCV and immunization coverage for individual vaccine series}

Additional analyses suggest that the decrease in probability of being up-to-date observed in Group $\mathrm{C}$ was not driven by disruptions in one vaccine series alone. Children in Group $\mathrm{C}$ were less likely to be up-to-date at the start of the PCV adoption period for hepatitis $\mathrm{B}$ vaccination (OR $=0.4,95 \% \mathrm{CI}: 0.2-0.8$ ) as well as for each of the other vaccine series (polio: $\mathrm{OR}=0.48,95 \% \mathrm{CI}: 0.24-$ 0.96; DTP: $\mathrm{OR}=0.65,95 \% \mathrm{CI}: 0.41-1.03$; Hib: $\mathrm{OR}=$ 


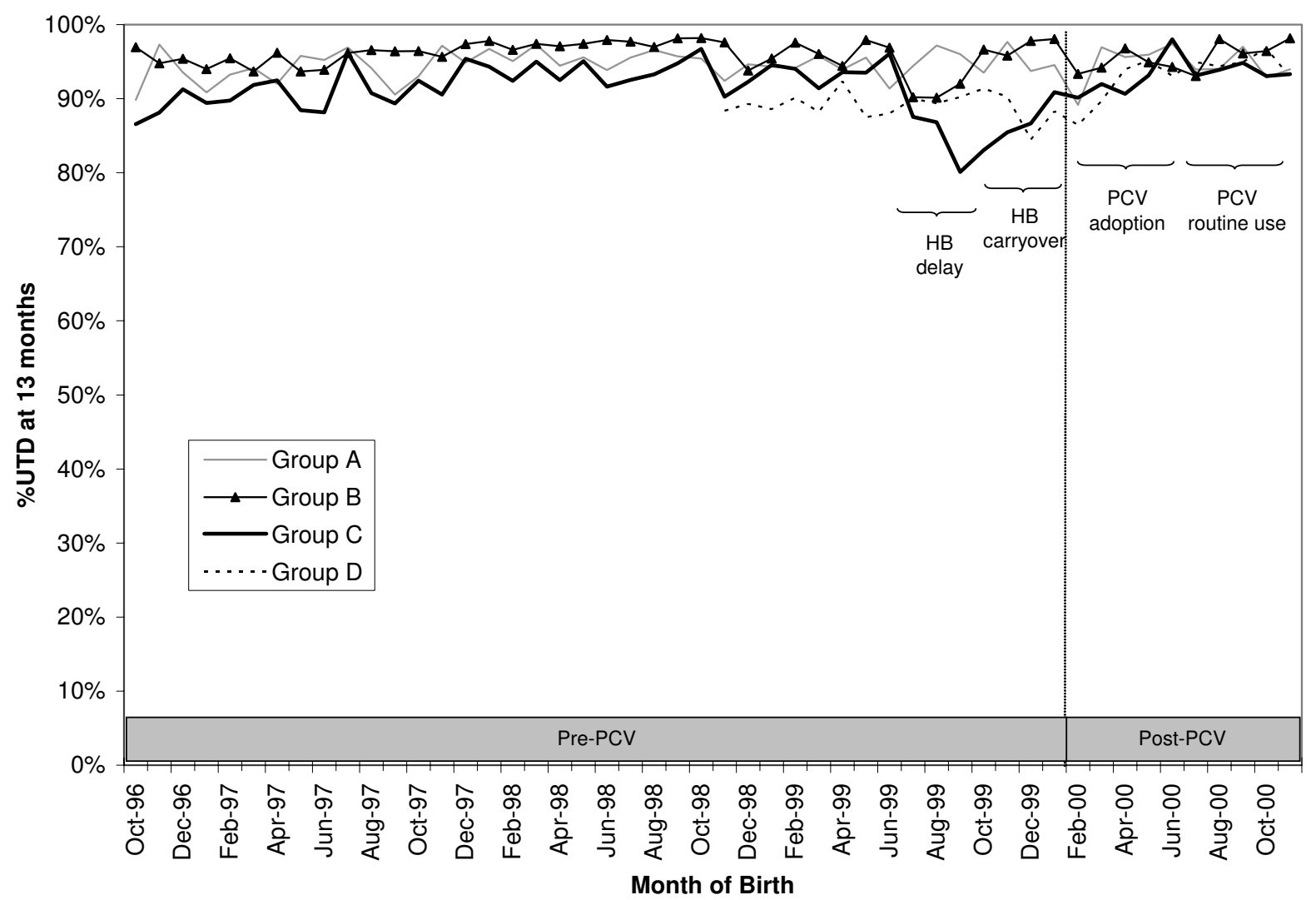

Figure 3

Percent up-to-date for non-PCV recommended vaccines at 13 months. Children were grouped by the month and year of their birth. Note: Data between April - October 1998 were considered incomplete in Group D due to a potential disruption in their immunization information system during the pre-PCV baseline period.

0.60; 95\% CI: 0.38 - 0.96). These effects persisted after PCV entered routine use for the polio $(\mathrm{OR}=0.48,95 \% \mathrm{CI}$ : 0.23-1.01), DTP (OR = 0.5, 95\% CI: 0.3-0.9) and Hib $(\mathrm{OR}=0.5,95 \% \mathrm{CI}: 0.3-0.9)$ vaccine series compared to baseline. In the three provider groups where PCV introduction was not associated with changes in up-to-date coverage among 13-month-olds, no systematic differences in coverage for individual vaccine series were observed. Similar broader disruptions across individual vaccine series were observed for the impact of PCV on the time spent underimmunized by13 months (data not shown).

\section{Discussion}

In our study of four large provider group populations, the introduction of PCV was not associated with a substantial adverse impact on a child's probability of being up-to- date at 13 months for non-PCV recommended childhood vaccines. We did find moderate increases in time spent underimmunized in some provider groups, although these delays likely did not result in clinical harm. Our findings suggest that the timeliness of immunization for several vaccine series was likely adversely affected by either PCV introduction or the hepatitis B birth dose suspension, although it was not possible to disentangle the effects of these two policy changes. Overall, our findings support continued vigilance during changes in immunization policy in order to mitigate unintended delays in vaccine delivery that may arise due to concerns about multiple injections.

Our finding of no major impact of PCV introduction on up-to-date status is consistent with reports that increases in the number of vaccine injections have not led to clini- 
Table 2: PCV introduction and probability of being up-to-date at 13 months

\begin{tabular}{|c|c|c|c|c|c|c|c|c|}
\hline \multirow[b]{2}{*}{ Group } & \multicolumn{4}{|c|}{ Contrast $\boldsymbol{a}: \mathrm{PCV}$ adoption vs. predicted baseline } & \multicolumn{4}{|c|}{ Contrast b: PCV routine vs. predicted baseline } \\
\hline & Odds ratio & $95 \% \mathrm{Cl}$ & $\begin{array}{c}\text { Fitted } \\
\text { probability }\end{array}$ & $\begin{array}{l}\text { Predicted } \\
\text { probability }\end{array}$ & Odds ratio & $95 \% \mathrm{Cl}$ & $\begin{array}{c}\text { Fitted } \\
\text { probability }\end{array}$ & $\begin{array}{l}\text { Predicted } \\
\text { probability }\end{array}$ \\
\hline Group A & 1.0 & $0.5-1.8$ & 0.95 & 0.95 & 0.8 & $0.4-1.4$ & 0.94 & 0.95 \\
\hline Group B & 0.5 & $0.2-1.2$ & 0.96 & 0.98 & 0.7 & $0.3-1.5$ & 0.97 & 0.98 \\
\hline Group C & 0.5 & $0.4-0.8$ & 0.92 & 0.95 & 0.5 & $0.3-0.8$ & 0.93 & 0.96 \\
\hline Group D & 1.2 & $0.5-2.9$ & 0.90 & 0.89 & 2.0 & $0.6-7.0$ & 0.94 & 0.88 \\
\hline
\end{tabular}

Contrast $\boldsymbol{a}$ compares a child's probability of being up-to-date at 13 months among the February 2000 birth cohort to that predicted from the prePCV baseline trend. Contrast $\boldsymbol{b}$ compares a child's probability of being up-to-date at 13 months among the July 2000 birth cohort to that predicted from the pre-PCV baseline trend. For each contrast, the "fitted probability" was the probability of being up-to-date as fitted from the multivariate regression models based on the observed data and the "predicted probability" was extrapolated from the pre-PCV baseline trend.

cally important reductions in immunization coverage[11]. While providers and parents have expressed concerns regarding multiple injections, $[4,6,20,21]$ many parents still prefer that all recommended vaccines be given at one visit[20]. Recent surveys also suggest that providers are now more willing to administer multiple injections $[7,21,22]$. These findings are consistent with results from the 2003 National Immunization Survey, [23] which indicate that coverage levels for other childhood vaccines among children aged 19-35 months of age had been maintained during the adoption of PCV.

The heterogeneity in the response to PCV introduction observed across the sites may have arisen due to a variety of reasons. Responses to hepatitis B policy changes differed across the provider groups, and only those sites that experienced disruptions during the hepatitis B delay and carryover periods had lower immunization coverage following PCV introduction. If the effects of the hepatitis B vaccination policy reversals lingered as PCV entered routine use in our health plan populations (i.e., 10 months after reinstatement of the birth vaccination recommendations), our study would be unable to fully disentangle the relative contributions of these two policies. Availability of the hepatitis B-Hib combination vaccine may simplify immunization scheduling by reducing the total number of shots a child receives during the first year of life,[24] and the differential adoption of the combination hepatitis B-hib vaccine may have influenced the variation observed across provider groups. The routine use of the combination hepatitis B-Hib vaccine in Group A throughout the study period may have made immunization scheduling less sensitive to the temporary hepatitis $\mathrm{B}$ birth dose suspension or alleviated concerns about multiple injections related to the introduction of PCV.

Implementation of the hepatitis B-Hib combination vaccine during the study period in Group C and Group D may also have influenced the impact of PCV introduction on immunization coverage in these settings; however, the coincident timing of the implementation of the hepatitis $\mathrm{B}$-Hib combination vaccine with the temporary hepatitis B birth dose suspension (Group D) and PCV adoption (Group D) limits our ability to determine separate effects for these policy changes in our analysis. We also compared immunization coverage for non-PCV vaccinations following PCV introduction with predictions of immunization coverage extrapolated from baseline trends. Dependent on the level of baseline immunization coverage, expectation of a continued constant trend in immu-

Table 3: PCV introduction and probability of never being underimmunized by 13 months of age

\begin{tabular}{|c|c|c|c|c|c|c|c|c|}
\hline \multirow[b]{2}{*}{ Group } & \multicolumn{4}{|c|}{ Contrast a: PCV adoption vs. pre-PCV baseline } & \multicolumn{4}{|c|}{ Contrast b: PCV routine vs. pre-PCV baseline } \\
\hline & Odds ratio & $95 \% \mathrm{Cl}$ & $\begin{array}{c}\text { Fitted } \\
\text { probability }\end{array}$ & $\begin{array}{l}\text { Predicted } \\
\text { probability }\end{array}$ & Odds ratio & $95 \% \mathrm{Cl}$ & $\begin{array}{c}\text { Fitted } \\
\text { probability }\end{array}$ & $\begin{array}{l}\text { Predicted } \\
\text { probability }\end{array}$ \\
\hline Group A & I.I & $0.7-1.6$ & 0.83 & 0.82 & I.I. & $0.7-1.8$ & 0.86 & 0.85 \\
\hline Group B & 0.4 & $0.3-0.5$ & 0.55 & 0.77 & 0.4 & $0.3-0.6$ & 0.65 & 0.81 \\
\hline Group C & 0.33 & $0.26-0.42$ & 0.34 & 0.60 & 0.5 & $0.4-0.7$ & 0.58 & 0.72 \\
\hline
\end{tabular}

Contrast $\boldsymbol{a}$ compares a child's probability of spending zero days underimmunized by I 3 months among the February 2000 birth cohort based on the observed data to that predicted from the pre-PCV baseline trend. Contrast $b$ compares a child's probability of spending zero days underimmunized by 13 months among the July 2000 birth cohort based on the observed data to that predicted from the pre-PCV baseline trend. For each contrast, the "fitted probability" was the probability of spending no time underimmunized as fitted from the multivariate regression models and the "predicted probability" was extrapolated from the pre-PCV baseline trend. 
nization coverage may have yielded an overestimate of the extent of disruption in immunization coverage in some settings. It is reassuring that PCV introduction was not associated with clinically important reductions in immunization coverage, even given expectations of a linear trend predicted from baseline. Finally, flexibility in immunization guidelines or expectations regarding the simultaneous administration of vaccines may vary across sites and influence variation in immunization scheduling.

This study evaluates the impact of introduction of the PCV policy and not whether administration of PCV to a given child affects that individual's probability of being up-todate. Given the rapid adoption of PCV in the four provider groups, we are able to estimate the net effect of integration of PCV into the childhood immunization schedule. Information on certain demographic factors (e.g., race/ethnicity, socioeconomic status) was not routinely collected across these settings, and we were unable to directly assess the effects of these characteristics in the analysis. However, by comparing birth cohorts across the study period, only those characteristics whose distribution in the study population changed concurrently with the time of introduction of PCV can act as potential confounders. No major changes in the coverage plans offered by these health plans occurred at the time of PCV introduction, and we therefore would not expect the demographic characteristics of the enrolled populations in these provider groups to have changed dramatically concurrent with introduction of the new PCV policy.

Finally, this study was conducted in health plan populations, who are mostly privately insured and have good access to health care. The study population was additionally restricted to children who were continuously enrolled during the first year of life; these children are likely to have experienced less scattering of their immunization records and to have had more opportunities to catch-up on immunizations. While children in the study population are thus likely to have higher overall immunization coverage than might be expected for the general population, comparison across similarly restricted birth cohorts remains valid to evaluate the potential impact of the introduction of PCV. In addition, earlier evaluations of the impact of the transition from oral polio vaccine to inactivated (injected) polio vaccine have yielded similar findings of a lack of an adverse effect on immunization coverage among children enrolled in managed care populations[11] and among children receiving vaccinations in public clinics[20].

\section{Conclusion}

The continued development and addition of new vaccines to the childhood immunization schedule is likely to exacerbate concerns regarding simultaneous multiple injec- tions. Our findings indicate that these provider groups remained capable of absorbing the most recent increases in multiple injections with minimal impact on up-to-date measures. However, the timeliness of delivery may have been affected by the introduction of PCV and the suspension of the birth dose of hepatitis B vaccine. This study highlights the continuing need to monitor the impact of new vaccines as well as vaccine-safety related policy decisions that affect immunization scheduling.

\section{Competing interests}

The author(s) declare that they have no competing interests.

\section{Authors' contributions}

NDL participated in the design of the study, analysis and interpretation of results, and manuscript preparation and revision. KK participated in the design of the study, interpretation of results, and manuscript revision. KAC participated in the design of the study, interpretation of results, and manuscript revision. XY participated in the acquisition of data, analysis and interpretation of the results, and manuscript preparation. EKF, SX, FW, and JM were involved in the acquisition of data, interpretation of results, and manuscript revision. JS was involved in the interpretation of results and manuscript revision. TAL participated in the design of the study, acquisition of data, analysis and interpretation or results, and manuscript revision.

\section{Acknowledgements}

This study was supported by the Centers for Disease Control and Prevention, Atlanta, GA, via cooperative agreement UR6/CCUII76II and contract 200-2002-00732 (the Vaccine Safety Datalink Project) with America's Health Insurance Plans. Dr. Lin's effort was supported in part by the Agency for Healthcare Research and Quality, National Research Service Award, grant number HS000028-19. Dr. Lin is currently an AHRQ Trainee at the Center for Health Policy, Stanford University, Stanford, California.

We gratefully acknowledge our colleagues at the Department of Ambulatory Care and Prevention, especially Megan O'Brien, MPH, for local coordination of the VSD project, Richard Fox, MA, for his management of the automated analytic databases, Jyotsna Dhall, MPH, for initial dataset preparation for this work, and Richard Platt, MD, MPH, for his senior leadership of the project. We appreciate the contributions of Nicolle Mode, MPH (HealthPartners Research Foundation), Karen Riedlinger, MPH (Kaiser Permanente Northwest), and Renae Smith-Ray (Kaiser Permanente Colorado) who prepared the analytic databases at each of the health plans in this study. We thank Robert Davis, MD, MPH, for thoughtful advice, and we appreciate the guidance of our other collaborators at the National Immunization Program, including Robert Chen, MD, David Shay, MD, MPH, and Frank DeStefano, MD.

The Vaccine Safety Datalink Team at the time of this study included Frank DeStefano, MD, MPH, Robert T Chen, MD, David Shay, MD, MPH, Philip $\mathrm{H}$ Rhodes, PhD, Margarette Kolzcak, PhD, Julianne Gee, MPH, Robert L Davis, MD, MPH, William Thompson, PhD, James Baggs, PhD, Brooke Barry, Carolyn Bridges, MD, Scott Campbell, Chris Casey, Jufu Chen, PhD, 
Charissa Denson, David Elswich, Gary Euler, Paul Gargiullo, Rafael Harpaz, Beth Hibbs, Aisha Jumaan, David King, Katrin S Kohl, MD, MPH, Piotr Kramarz, MD, Gina Mootrey, John Moran, Pekka Nuorti, Vitali Pool, MD, James Singleton, Eric Weintraub, Bruce Weniger, MD, MPH, Melinda Wharton, Fujie Xu, and Weigong Zhou, MD, PhD (Centers for Disease Control and Prevention, Atlanta, GA); M Miles Braun, MD, MPH, Robert P Wise, MD, MPH, Robert Ball, MD, MPH, Dale Burwen MD, MPH, David Davis, Hector Izurieta, Ann W McMahon, MD, MS, Fred Varricchio MD, PhD, and Jane Woo MD, MPH (Food and Drug Administration, Bethesda, MD); Lisa Jackson, MD, MPH, Patti Benson, MPH, Kari Bohlke, ScD, Barbara Carste, MPH, John Dunn, MD, MPH, Christi Hanson, BA, Mike Jackson, Darren Malais, BS, Jennifer Nelson, PhD, Kathleen Neuzil, MD, MPH, Troy J Scott, Neil Vora, Onchee Yu, MS, and Ann Zavitkovsky, MPH (Group Health Cooperative, Seattle, WA); Tracy Lieu, MD, MPH, Richard Platt, MD, MS, Emily Cain, Jyotsna Dhall, MS, Jonathan Finkelstein, MD, MPH, Richard Fox, MSW, Charlene Gay, Katherine Hohman, Ken Kleinman, PhD, Martin Kulldorff, PhD, Grace Lee, MD, Nancy Lin, MS, Megan O'Brien, MPH, Lisa Prosser, PhD, Virginia Rego, MS, MPH, Katherine Yih, PhD, and Xian-Jie Yu, MS (Harvard Pilgrim Health Care/Harvard Medical School, Boston, MA); Mike Goodman, PhD, Jim Nordin, MD, Feifei Wei, PhD, Susan Adlis, Jerry Amundson, Renner Anderson, Amy Butani, Kelly Fillbrandt, Olga Godlevsky, Peter Harper, Leslie Kuckler, A. Marshall McBean, MD, MS, Maribet McCarty, Beth Molitor, Andrew Nelson, MPH, Kristin Nichol, MD, MPH, MBA, Eugene Sesonga, and Lynn Taliaferro (HealthPartners Research Foundation, Minneapolis, MN); Vito Caserta, MD, MPH and Geoffrey Evans, MD (Division of Vaccine Injury Compensation, Health Resources and Services Administration, Rockville, MD); Eric France, MD, Marcia Blake MA, MSPH, Jason Glanz, MS, Simon Hambidge, MD, PhD, James Kaferly, David L McClure, MS, Ronald Norman, Marsha Raebel, PharmD, Debra P Ritzwoller, PhD, Renae Smith-Ray, MA, Stanley $\mathrm{Xu}, \mathrm{PhD}$, and Kristi Yamasaki, PharmD (Kaiser Permanente Colorado, Denver, CO); Edward Belongia, MD, Nicholas Berger, Carol Beyer, James Donahue, DVM, PhD, Robert Greenlee, PhD, Juanita Herr, Burney Kieke, MS, Katherine Konitzer, Jordon Ott, Peggy Peissig, MS (Marshfield Clinic Research Foundation, Marshfield, WI); Steven B Black, MD, Laura Bracken, Diane Carpenter, Lisa Croen, Robert Davis, MD, MPH, Ajit Gemunu de Silva, Bruce H Fireman, MA, Patti Hallam, John Hansen, BA, Ned Lewis, MPH, Regina L Mason, Roxana Odouli, Paula Ray, MPH, Pat Ross, Joan Schwalbe, Henry R Shinefield, MD, Stanley Watson, Cathleen Yoshida, and Lea Q Zhang (Kaiser Permanente of Northern California, Oakland, CA); John P Mullooly, PhD, Allison Naleway PhD, Steven L Balch, Michael Barrett, MD, Alan Bauck, BS, Cathy Briggs, Marina Britsky, Andrea Brown, Colleen Chun, MD, Brad Crane, MS, Lois Drew, BA, Shannon Edie, Terri Haswell, Benjamin Drew Horning, Weiming Hu, Jill Mesa, John A Pearson, MD, Karen Riedlinger, MPH, Roberleigh Schuler, MS, Jerry Slepack, MD, Loie Drew, Gayle Thomas-Monk, Mike Thornton, Kathryn Torvik, Amy Triebwasser, and Sheila Weinmann, PhD (Kaiser Permanente Northwest Region, Portland, OR); Joel I Ward, MD, Constance M Vadheim, PhD, Ken Zangwill, MD, Eileen Eriksen, MPH, Jennifer Lee, MS, Jennie Jing, MA, and Nancy Goff (Center for Vaccine Research, Harbor-UCLA Medical Center, Torrance, CA); S. Michael Marcy, MD, Marlene M Lugg, DrPH, Jag Batra, MD, Monique Bryher, MSPH, Susan Butler, Frederico Canton, Chung-Yin Chiu, MS, and Martin Lee, PhD (Southern California Kaiser Permanente, Los Angeles, CA).

\section{References}

I. Recommended childhood immunization schedule--United States, 2002. MMWR Morb Mortal Wkly Rep 2002, 5I(2):3I-33.

2. Atkinson WL, Pickering LK, Schwartz B, Weniger BG, Iskander JK, Watson JC: General recommendations on immunization Recommendations of the Advisory Committee on Immunization Practices (ACIP) and the American Academy of Family Physicians (AAFP). MMWR Recomm Rep 2002, 5 I (RR-2): I-35.
3. Zimmerman RK, Schlesselman J], Baird AL, Mieczkowski TA: A national survey to understand why physicians defer childhood immunizations. Arch Pediatr Adolesc Med 1997, I 5 I (7):657-664.

4. Schaffer SJ, Szilagyi PG, Shone LP, Ambrose SJ, Dunn MK, Barth RD, Edwards K, Weinberg GA, Balter S, Schwartz B: Physician perspectives regarding pneumococcal conjugate vaccine. Pediatrics 2002, I I 0(6):e68.

5. Woodin KA, Rodewald LE, Humiston SG, Carges MS, Schaffer SJ, Szilagyi PG: Physician and parent opinions. Are children becoming pincushions from immunizations? Arch Pediatr Adolesc Med 1995, | 49(8):845-849.

6. Lee KC, Finkelstein JA, Miroshnik IL, Rusinak D, Santoli JM, Lett SM, Lieu TA: Pediatricians' self-reported clinical practices and adherence to national immunization guidelines after the introduction of pneumococcal conjugate vaccine. Arch Pediatr Adolesc Med 2004, I 58(7):695-70I.

7. Davis MM, Ndiaye SM, Freed GL, Clark SJ: One-year uptake of pneumococcal conjugate vaccine: a national survey of family physicians and pediatricians. I Am Board Fam Pract 2003, I 6(5):363-37|

8. Chen RT, Glasser JW, Rhodes PH, Davis RL, Barlow WE, Thompson RS, Mullooly JP, Black SB, Shinefield HR, Vadheim CM, Marcy SM, Ward JI, Wise RP, Wassilak SG, Hadler SC: Vaccine Safety Datalink project: a new tool for improving vaccine safety monitoring in the United States. The Vaccine Safety Datalink Team. Pediatrics 1997, 99(6):765-773.

9. Preventing pneumococcal disease among infants and young children. Recommendations of the Advisory Committee on Immunization Practices (ACIP). MMWR Recomm Rep 2000, 49(RR-9): I-35.

10. Rodewald L, Maes E, Stevenson J, Lyons B, Stokley S, Szilagyi P: Immunization performance measurement in a changing immunization environment. Pediatrics 1999, 103(4 Pt 2):889-897.

II. Davis RL, Lieu TA, Mell LK, Capra AM, Zavitkovsky A, Quesenberry CPJ, Black SB, Shinefield HR, Thompson RS, Rodewald LE: Impact of the change in polio vaccination schedule on immunization coverage rates: a study in two large health maintenance organizations. Pediatrics 2001, 107(4):671-676.

12. Thimerosal in vaccines: a joint statement of the American Academy of Pediatrics and the Public Health Service. MMWR Morb Mortal Wkly Rep 1999, 48(26):563-565.

13. Availability of hepatitis $B$ vaccine that does not contain thimerosal as a preservative. MMWR Morb Mortal Wkly Rep 1999, 48(35):780-782

14. Oram RJ, Daum RS, Seal JB, Lauderdale DS: Impact of recommendations to suspend the birth dose of hepatitis $B$ virus vaccine. Jama 200I, 285(14): 1874-1879.

I5. Clark SJ, Cabana MD, Malik T, Yusuf H, Freed GL: Hepatitis B vaccination practices in hospital newborn nurseries before and after changes in vaccination recommendations. Arch Pediatr Adolesc Med 200I, I 55(8):915-920.

16. Hurie MB, Saari TN, Davis JP: Impact of the Joint Statement by the American Academy of Pediatrics/US Public Health Service on thimerosal in vaccines on hospital infant hepatitis $B$ vaccination practices. Pediatrics 200I, I07(4):755-758.

17. Biroscak BJ, Fiore AE, Fasano N, Fineis P, Collins MP, Stoltman G: Impact of the thimerosal controversy on hepatitis $B$ vaccine coverage of infants born to women of unknown hepatitis $B$ surface antigen status in Michigan. Pediatrics 2003, I I I (6 Pt I):e645-9

18. Lachenbruch PA: Analysis of data with excess zeros. Stat Methods Med Res 2002, I I (4):297-302.

19. Agresti A: Categorical data analysis. New York, Wiley; 1990.

20. Kolasa MS, Petersen TJ, Brink EW, Bulim ID, Stevenson JM, Rodewald LE: Impact of multiple injections on immunization rates among vulnerable children. Am J Prev Med 200I, 2 I (4):26I-266.

21. Davis MM, Andreae M, Freed GL: Physicians' early challenges related to the pneumococcal conjugate vaccine. Ambul Pediatr 200I, I(6):302-305.

22. Meyerhoff A, Jacobs RJ, Greenberg DP, Yagoda B, Castles CG: Clinician satisfaction with vaccination visits and the role of multiple injections, results from the COVISE Study (Combination Vaccines Impact on Satisfaction and Epidemiology). Clin Pediatr (Phila) 2004, 43(I):87-93. 
23. National, state, and urban area vaccination coverage among children aged 19-35 months--United States, 2003. MMWR Morb Mortal Wkly Rep 2004, 53(29):658-66I.

24. Davis RL, Coplan P, Mell L, Black S, Shinefield H, Lewis E: Impact of the introduction of a combined Haemophilus $B$ conjugate vaccine and hepatitis $B$ recombinant vaccine on vaccine coverage rates in a large West Coast health maintenance organization. Pediatr Infect Dis J 2003, 22(7):657-658.

\section{Pre-publication history}

The pre-publication history for this paper can be accessed here:

http://www.biomedcentral.com/1471-2431/5/43/prepub

Publish with Biomed Central and every scientist can read your work free of charge

"BioMed Central will be the most significant development for disseminating the results of biomedical research in our lifetime. "

Sir Paul Nurse, Cancer Research UK

Your research papers will be:

- available free of charge to the entire biomedical community

- peer reviewed and published immediately upon acceptance

- cited in PubMed and archived on PubMed Central

- yours - you keep the copyright

Submit your manuscript here:

http://www.biomedcentral.com/info/publishing_adv.asp
BioMedcentral 